\title{
CORRESPONDENCE
}

We welcome letters to the Editor concerning articles which have recently been published. Such letters will be subject to the usual stages of selection and editing; where appropriate the authors of the original article will be offered the opportunity to reply.

Letters should normally be under $\mathbf{5 0 0}$ words in length, doublespaced throughout, signed by all authors and fully referenced. The edited version will be returned for approval before publication.

\section{NITROGEN FREEZING OF MUSCLE GRAFTS}

Sir,

In the past you have published a number of papers from myself and my colleagues concerning the use of muscle denatured in liquid nitrogen as a means of repairing peripheral nerves (Norris et al 1988). We have also provided detailed findings on the importance of the morphological changes in the graft which are produced by freezing in liquid nitrogen (Glasby et al 1986; Glasby 1990).

It has come to my attention that a number of clinicians are now testing this method in practice but are using aerosol sprays to obtain freezing. As far as I am aware there is no published evidence that this method achieves the same essential morphological damage as does liquid nitrogen. The use of unproved methods of freezing may well be unsatisfactory and give poor results. It is depressing to see surgical expediency outrunning the proper use of scientific method.

Those who use aerosol sprays should be required to justify their use in a scientific way which parallels the data painstakingly obtained in our laboratory for properly nitrogen-frozen muscle grafts.

M. A. GLASBY, MA, MSc, FRCS

Department of Anatomy

University of Edinburgh

Edinburgh, UK.

Glasby MA, Gschmeissner SG, Hitchcock RJI, Huang CL-H. The dependence of nerve regeneration through muscle grafts in the rat on the availability and orientation of basement membrane. Neurocytol 1986; 15:497-510.

Glasby MA. Nerve growth in matrices of orientated muscle basement membrane: developing a new method of nerve repair. Clin Anat $1990 ; 3: 161-82$.

Norris RW, Glasby MA, Gattuso JM, Bowden REM. Peripheral nerve repair in humans using muscle autografts: a new technique. J Bone Joint Surg [Br] 1988; 70-B:530-3.

\section{THROMBOSIS AND EMBOLISM AFTER KNEE ARTHROPLASTY}

Sir,

I read with interest the recent paper by Haas et al entitled 'The significance of calf thrombi after total knee arthroplasty' (1992; 74-B:799-802). This is an important and welcome study, but I have two reservations about the conclusions reached.

First, the criteria for the diagnosis of pulmonary embolism

(C)1993 British Editorial Society of Bone and Joint Surgery 0301-620X/93/3568 \$2.00

J Bone Joint Surg [Br] 1993; 75-B: 507-9. on a perfusion-only scan are difficult to establish. In this paper the appearance of a new or larger defect on the postoperative scan which was not present preoperatively was taken as evidence of an embolism. There are many reasons for areas of decreased perfusion (particularly at the apices) in the few days after surgery; without the benefit of a concomitant ventilation scan, the diagnosis of pulmonary embolism is at best presumptive.

Secondly, assessment of the venous system by 'snap-shot' venography does not provide information on the dynamic process of thrombogenesis. The finding of a thrombus in the calf veins only does not exclude the previous presence of a proximal thrombus, which has since embolised or even resolved. It is therefore perhaps misleading to attribute all emboli in patients with venographic calf thrombosis to these thrombi. Only serial, dynamic assessment with non-invasive tests will allow this issue to be settled.

The risk of fatal or even symptomatic pulmonary embolism from isolated calf thrombosis is very small; it does not merit the considerable risk of anticoagulation in elderly patients, particularly as such therapy does not prevent propagation (Strandness 1990; Maynard, Sculco and Ghelman 1991). It would be unfortunate if this paper increased the incidence of morbidity from anticoagulation inappropriately prescribed for thrombosis confined to the calf veins.

M. A. MCNALLY, FRCS

British Orthopaedic Association Wishbone Research Fellow Department of Orthopaedic Surgery

The Queen's University Of Belfast

Musgrave Park Hospital

Belfast, UK.

Haas SB, Tribus CB, Insall JN, Becker MW, Windsor RE. The significance of calf thrombi after total knee arthroplasty. $J$ Bone Joint Surg [ Br] 1992; 74-B :799-802.

Maynard MJ, Sculco TP, Ghelman B. Progression and regression of deep vein thrombosis after total knee arthroplasty. Clin Orthop $1991 ; 273: 125-30$.

Strandness DE, Jr. Thrombus propagation and level of anticoagulation $J$ Vasc Surg 1990; 12:497-8.

Authors' reply:

Sir,

Thank you for the opportunity to respond to the letter from $\mathrm{Mr}$ McNally.

We agree with him that perfusion lung scans are less accurate in the diagnosis of pulmonary embolism than combined ventilation/perfusion scans. While this may have overestimated the overall rate of asymptomatic pulmonary embolism, there is no reason to assume that it affected the relative rate. Our study showed that patients with calf thrombi had a rate of positive lung scans over three times greater than that of patients with no evidence of thrombosis. This indicated that patients with calf thrombi are at increased risk of pulmonary embolism when compared with patients without thrombi. Lotke, Wong and Ecker (1986), using ventilation/perfusion lung scans, showed that patients with thromboses had a three-times-higher rate of high-probability lung scans compared with patients with negative venograms: $27 \%$ versus $9 \%$.

We also agree that thrombogenesis is a dynamic process. In fact, we believe that the greatest risk of calf thrombi is due to the fact that these clots may continue to propagate into the 